\title{
Busting myths about "species"
}

\author{
Charles H Pence
}

Keywords: Species; Essentialism; Aristotle; Plato; Ernst Mayr; History of biology

\section{Book details}

Wilkins, John S. Species: A History of the Idea

Berkeley, CA: University of California Press, 2009. xiv + 288 pp., index, ISBN 9780520260856.

\section{Species}

A History of the Idea, by John S. Wilkins. Berkeley, CA: University of California Press, 2009. Pp. xiv +288 , index. $\mathrm{H} / \mathrm{b} \$ 31.95$.

It is a claim often repeated, and reinforced by the periodic publication of hefty monographs on the subject (Coyne and Orr 2004), that there is a "species problem" in evolutionary biology. Ernst Mayr, in his 1942 book, wrote it into the ground floor of the New Synthesis. But what, exactly, is the species problem - and, perhaps more importantly, how did it arise in the first place? John Wilkins's book admirably tackles the first question by means of the second - offering a deep, thorough, and contextualized understanding of the species problem, clarifying a number of essential issues in that debate, and, in the process, correcting a number of persistent misconceptions about the idea of species from Plato to Darwin.

An encyclopedic work with an impressively broad scope, Wilkins's Species falls, broadly, into two parts. The first narrates the history of the concept of species from its roots in Plato and Aristotle to Darwin's development of evolutionary theory. After a brief bridge, the second looks at the roots of the contemporary species problem, laying out both its historical outlines and the vast array of contemporary positions one finds in the debate over the concept of species. Let's consider each in turn.

Correspondence: charles@charlespence.net

Department of Philosophy and Religious Studies, Louisiana State University, 102 Coates Hall, Baton Rouge, LA 70803, USA

\section{"Species" from Plato to Darwin}

With regard to the development of the concept of species before Darwin, Wilkins rightly notes that there is an accepted, standard narrative of this history, constructed, as he deftly shows, by biologists during the New Synthesis (around 1958, in fact; p. xi). The "received view" goes something like this. Taking a combination of Platonist essentialism and Aristotelian logic as a basis, the "species concept" of Linnaeus and all others before Darwin holds that species are permanent, eternal, fixed objects consisting of a set of essential or typical properties, deviations from which can at best be monstrous. This is the bogeyman which Mayr labeled "typological thinking" (Mayr 1959), and, as the story goes, one of Darwin's greatest accomplishments was its overthrow and replacement by "population thinking", the recognition that species are in fact just a particular kind of population, and are connected by common descent.

What is remarkable about this received history is that, under the sustained and careful scrutiny of a scholar such as Wilkins, none of it turns out to be correct.

First, essentialism. Wilkins argues that the idea that biological species have essences is based on a pervasive misreading of ancient and medieval philosophical works, a conflation between a logical concept of species (used in the Aristotelian enterprise of categorization or classification of all objects and ideas, not just organisms) and a biological concept of species (the one familiar today). The latter - the idea that there could be such a thing as a distinctively biological concept of species - dates only from the seventeenth century (p. 9). One must, therefore, be exceedingly careful drawing any conclusions about biological "species" prior to 1600 .

When sufficient care is applied to the ancient and medieval sources, then, we find that natural history in these periods is not "essentialist" in the pernicious sense that Mayr ascribes, but rather in the more benign manner that Wilkins dubs typology (not to be confused with 
Mayr's use of "typological thinking"). Ancient and medieval natural historians were interested in describing various characteristics of organisms that could be used to diagnostically determine species membership in the field, much like the work of today's systematists. Far from being some sort of concrete essence that must be exemplified by every organism in the species, types (then, as now) can be exemplified to greater or lesser extents, and can be varied from (p. 91) - and this is not an innovation brought about by Darwin, but can be found dating all the way back to Aristotle (p. 232). As Wilkins says, "[t]here is everywhere a remarkable lack of the sort of essentialism that Mayr and others believe permeates this period and its philosophy. While we see typology, when it comes to dealing with biological organisms, most of the time there is no insistence on essences" (pp. 228-9).

Finally, far from being some sort of static or fixed notion, Wilkins shows that the concept of species has (again, as far back as Aristotle) always involved what he calls a generative conception of species. That is, the very idea of species fundamentally comprises, at least in part, the preservation of form over time and its transmission from one generation to the next (p. xi). It is not Darwin that supplants this view, but genetics, in finally discovering the material basis for this temporal transmission.

This is not to say that there is no such thing as a fixed notion of species prior to Darwin. The first proponent of species fixism was John Ray, a seventeenth-century British naturalist. Ray - the first philosopher ever to develop a concept of classification that was exclusive to the biological realm - argued that species are fixed in number from the time of God's creation (p. 67). Ray's view, in turn, is picked up by Linnaeus, who claimed that each species was created specially by God and fixed from that point forward (resulting in his famous dictum that "there are as many species as the Infinite Being produced diverse forms in the beginning," p. 72). But rather than being the result of some throwback to Platonist forms or Aristotelian logic, species fixism is the result of a religious response to the debates between preformationism and epigenesis in embryological development (p. 95). "[I]t is not that species were not held to be fixed before the seventeenth century," Wilkins writes - "they simply had no idea of a biological species" (p. 94).

The early nineteenth century - the background, that is, for the introduction of Darwin's work - was dominated by the twin influences of the generative conception of species and the idea of species fixism (p. 127). To draw on only two of Wilkins's many examples, Cuvier's geological catastrophism claims that "species come into existence at the beginning of each geological epoch and never vary thereafter" (p. 109), while Agassiz (the closest thinker, Wilkins argues, to the straw man of Mayr's "typological thinking") did indeed believe that species carried fixed essences in the mind of God, were unable to vary over time, and that those essences genuinely caused the characteristics of those species, rather than merely serving as diagnostic characteristics to determine species membership.

\section{"Species" in the work of Darwin}

Darwin's own thoughts about species are the subject of no small quantity of debate. It is a common trope in the literature - Wilkins cites both Futuyma (1983) and Coyne and Orr (2004) - that Darwin's Origin of Species didn't really describe the origins of species, because Darwin lacked a clear concept of just what species are, and didn't spend much time considering the mechanisms of speciation. While remaining cognizant of the development of Darwin's views over time (from the early notebooks through the Origin and his later works), Wilkins clearly demonstrates that both of these claims are false.

Early in his career, especially in the notebooks, Darwin believes that geographical isolation is an absolutely essential ingredient in the formulation of new species (p. 148). By the time of the Origin, and through the works which came after it, he has modified his view, giving pride of place rather to natural selection as the driver of speciation events - regardless of the presence or absence of geographic isolation. And despite the fact that Darwin's language seems to sound at times as though he believes that species are only terms of convenience for the use of taxonomists, Wilkins argues that the preponderance of the evidence weighs in favor of Darwin's having believed that, while the distinctions between groups of organisms themselves, in the natural world, are genuine, the dividing line between a species and a variety is an arbitrary one, drawn for the benefit of the biologist (p. 144).

As is often the case in Darwin scholarship, evaluating Wilkins's approach to Darwin's use of species is a significant undertaking, and would lead us too far afield. I will mention only that he (here, as throughout the work) appeals to an exceptionally broad spectrum of primary source material, making his analysis wide-ranging and comprehensive.

Darwin's own views lead quite quickly to the nowfamiliar landscape of the debates over species in evolutionary theory. As early as 1889 , we begin to see the battle lines drawn between allopatric and sympatric theories of speciation. The first essay to attempt to parse out all "logically possible" definitions of the concept of species is authored by George Romanes in 1895 (p. 167), and Wilkins dates the beginning of the fully fledged "species problem" to an essay by E. B. Poulton in 1903 (p. 173).

\section{The species problem}

What, then, is the species problem? Prior to the work of Darwin, work on the idea of species concerns almost exclusively how it is that species come to be in the first 
place. But after Darwin, we have ready accounts of the production of species (whether by natural selection or other causal mechanisms), and a different problem - the "species problem" in its modern guise - comes to the fore. What is it that marks out a species, as a population engaged in some sort of gradual process of change, as a genuine species? In Wilkins's words, "[i]t is the problem of defining what rank it might be that species achieve when they become species" (p. 173).

Dobzhansky, Wilkins claims, is the first to lay out this problem with real clarity. The definition of the concept of species is an easy one to determine, he claims species are simply groups of individuals which are interfertile, but somehow physiologically prevented from interbreeding with other species (p. 184). The gradual nature of evolution, however, may make it impossible in practice, at least in some cases, to determine whether or not we have completely attained that separation (p. 185). Huxley, on the other hand, took this difficulty in practice to entail a conceptual problem in the notion of species itself - casting doubt on the idea that there could be a single coherent definition of species at all (p. 188).

"Into this ambiguity of opinion came Ernst Mayr" (p. 188), the central figure in the development of the contemporary species problem. Mayr's biological species concept, developed over several decades beginning in 1940 (pp. 189-98), still casts a long shadow over our understanding of species in biology. Mayr's history, as we have seen, is highly suspect. His claim that there was a single concept of species from Plato to Linnaeus is simply wrong, as is his claim that species were understood to be constant, unchanging, that all deviations were considered imperfections or monsters, and so forth (p. 194). Nor was Mayr the first to have a "biological" notion of species - as we have seen, there has been an element of propagation, generation, transmission of form over time in the idea of species as applied to biology, dating all the way back to Aristotle (p. 195). It is here that we can see just how profitable Wilkins's historical analysis has really been.

Finally, the book closes with an extended discussion of some twenty-five "species concepts" that are currently at play in the literature, from Mayr's BSC and its descendants, to phylogenetic, evolutionary, ecological, and paleontological notions of species. While this chapter moves quickly, it constitutes an invaluable reference for anyone interested in rapidly coming up to speed with the landscape of this debate, and would make for a quality teaching tool. The book's conclusion is one of the best I have read in recent years, lucidly laying out the book's main points in only seven pages.

\section{Final thoughts}

It is difficult to find anything to dislike about Wilkins's study. The breadth of the work is staggering, and the amount of research that went into its discussion of every major intellectual figure and conceptual player in the species debates from Plato onward is readily apparent at every turn. Its audience is clearly, in the first instance, historians and philosophers of biology - but it is certainly written well enough to be readable by practicing biologists, secondary teachers, or anyone interested in the role of species in the history of biological thought.

More importantly, its corrective to the obviously problematic histories often told about the role of species from Plato to Darwin is essential. ${ }^{a}$ After Wilkins's analysis, it could not be clearer that Mayr's picture of "typological thinking" must be abandoned. His separation of "essentialism" in a pernicious sense from the still-common use of "typology" is a welcome clarification. And the detailed, comprehensive, and unified picture of the development of the concept of species from Aristotelian logic, through the development of biological taxonomy as a discipline in its own right, to the work of Darwin and the contemporary debates over the species problem, offers scholars a contextualized understanding of the use of "species" that is hard to match.

What of the prognosis? Wilkins doesn't pretend to offer a solution to the species problem, whatever it is that might mean. But he does argue - correctly, in my opinion - that the demise of what he calls the "essentialist myth" could go a long way toward making the debate over species more sophisticated and more tractable (pp. 233-4). This work is positioned exceptionally well to do just that.

\section{Endnote}

${ }^{a}$ For those interested in these problems, Wilkins's book is not the only recent offering in this area; see Sloan (2013) for a helpful essay review.

\section{Competing interests}

The author declares that he has no competing interests.

Received: 15 June 2014 Accepted: 21 August 2014

Published online: 09 September 2014

\section{References}

Coyne, JA, \& Orr, HA. (2004). Speciation. Sunderland, MA: Sinauer Associates. Futuyma, DJ. (1983). Science on Trial: The Case for Evolution. New York: Pantheon.

Mayr, E. (1942). Systematics and the Origin of Species from the Viewpoint of a Zoologist. New York: Columbia University Press.

Mayr, E. (1959). Darwin and the evolutionary theory in biology. In J Meggers (Ed.), Evolution and Anthropology: A Centennial Appraisal (pp. 1-10). Washington, DC: Anthropological Society of Washington.

Sloan, PR. (2013). The species problem and history. Studies in History and Philosophy of Biological and Biomedical Sciences, 44, 237-241. doi:10.1016/j. shpsc.2013.01.001.

doi:10.1186/s12052-014-0021-4

Cite this article as: Pence: Busting myths about "species". Evolution: Education and Outreach 2014 7:21. 